\title{
A new Inter-electrode coupling capacitance extraction method for deep-submicron AIGaN/GaN HEMTs
}

\author{
Xiaodong Zhao, Yuehang $\mathrm{Xu}^{\mathrm{a})}$, Zhang Wen, Yonghao Jia, \\ Tiedi Zhang, Bo Yan, and Ruimin Xu \\ School of Electronic Engineering, University of Electronic Science and Technology \\ of China, Chengdu 611731, China \\ a)yuehangxu@uestc.edu.cn
}

\begin{abstract}
The accurate extraction of inter-electrode coupling capacitances (IECCs) is a difficult but important issue in small-signal modeling of highly scaled transistors. In this paper, a new method of determining the IECCs for deep-submicron aluminium gallium nitride/gallium nitride ( $\mathrm{AlGaN} / \mathrm{GaN})$ high electron-mobility transistors (HEMTs) is proposed. The method uses the pinch-off S-parameters under large drain bias to eliminate the influence of intrinsic capacitance on IECCs extraction, thereby determining the reliable starting value of IECCs. Compared with the conventional method, this method not only greatly reduces the parameter searching range in final value optimization but also avoids the non-physical extraction value for intrinsic parameters. Using this method, we build a small-signal model for a $0.15 \mu \mathrm{m}$ gate-length GaN HEMT. The measured data show that this method has high precision and can be applied to the modeling of millimeter-wave GaN HEMTs.
\end{abstract}

Keywords: equivalent circuit model, GaN HEMTs, inter-electrode coupling capacitance, millimeter-waves, small-signal parameter extraction

Classification: Microwave and millimeter-wave devices, circuits, and modules

\section{References}

[1] A. Jarndal, et al.: "A new small-signal modeling approach applied to GaN devices,” IEEE Trans. Microw. Theory Techn. 53 (2005) 3440 (DOI: 10.1109/ TMTT.2005.857332).

[2] X. Luo, et al:: "Equivalent circuit model of millimeter-wave AlGaN/GaN HEMTs," IEICE Electron. Express 11 (2014) 20140613 (DOI: 10.1587/elex. 11.20140613).

[3] X. Zhao, et al.: "Temperature-dependent access resistances in large-signal modeling of millimeter-wave AlGaN/GaN HEMTs," IEEE Trans. Microw. Theory Techn. 65 (2017) 2271 (DOI: 10.1109/TMTT.2017.2658561).

[4] Y. Xu, et al.: “A scalable large-signal multiharmonic model of AlGaN/GaN 
HEMTs and its application in C-band high power amplifier MMIC," IEEE Trans. Microw. Theory Techn. PP (2017) 1 (DOI: 10.1109/TMTT.2017. 2669984).

[5] C. Rong, et al.: "A broadband microwave GaN HEMTs class EF3 power amplifier with $\pi$-type network," IEICE Electron. Express 14 (2017) 20170260 (DOI: 10.1587/elex.14.20170260).

[6] M. Rudolph: Nonlinear Transistor Model Parameter Extraction Techniques (Cambridge Univ. Press, Cambridge, 2011) 1st ed.

[7] A. R. Alt, et al:: "Transistor modeling: Robust small-signal equivalent circuit extraction in various HEMT technologies," IEEE Microw. Mag. 14 (2013) 83 (DOI: 10.1109/MMM.2013.2248593).

[8] Y. Karisan, et al.: "Lumped element equivalent-circuit modeling of millimeterwave HEMT parasitics through full-wave electromagnetic analysis," IEEE Trans. Microw. Theory Techn. 64 (2016) 1419 (DOI: 10.1109/TMTT.2016. 2549520).

[9] M. A. Alim, et al.: "Temperature effect on DC and equivalent circuit parameters of $0.15-\mu \mathrm{m}$ gate length $\mathrm{GaN} / \mathrm{SiC}$ HEMT for microwave applications," IEEE Trans. Microw. Theory Techn. 64 (2016) 3483 (DOI: 10.1109/TMTT.2016.2604815).

[10] D. Schwantuschke, et al:: "A fully scalable compact small-signal modeling approach for $100 \mathrm{~nm}$ AlGaN/GaN HEMTs," Proc. 8th EuMIC (2013) 284.

[11] Z. Wen, et al.: "An efficient parameter extraction method for GaN HEMT small-signal equivalent circuit model," Int. J. Numer. Model. 30 (2017) e2127 (DOI: 10.1002/jnm.2127).

[12] Y. N. Rorsman, et al:: "Accurate small-signal modeling of HFETs for millimeter-wave applications," IEEE Trans. Microw. Theory Techn. 44 (1996) 432 (DOI: 10.1109/22.486152).

\section{Introduction}

As the shrinking of device geometry and the increase of the operating frequency, the distributed parameter effect in aluminium gallium nitride/gallium nitride (AlGaN/GaN) high electron-mobility transistors (HEMTs) becomes more and more obvious. For deep-submicron devices operating at the millimeter-wave frequencies, electromagnetic coupling effect between gate fingers, drain and source electrodes is significant, and the inter-electrode coupling capacitances (IECCs) have an important effect on the extraction of access resistances and intrinsic parameters. The IECCs have become a necessary part of the equivalent circuit model for AlGaN/GaN HEMTs [1, 2, 3, 4], and these models are fundamental to the design of broadband high-efficiency amplifiers [5].

Fig. 1 is a typical GaN HEMTs small-signal equivalent circuit model that has been validated up to $60 \mathrm{GHz}$ [1]. The capacitances $\mathrm{C}_{\mathrm{gp}}, \mathrm{C}_{\mathrm{dp}}$, and $\mathrm{C}_{\mathrm{gdp}}$ account for parasitic elements due to the pad, probes, and probe to probe coupling [1], and can be de-embedded from the measured S-parameters using test structures $[2,6,7]$. The starting values (for further optimization) of gate, drain, and source electrodes inductance $\mathrm{L}_{\mathrm{g}}, \mathrm{L}_{\mathrm{d}}$, and $\mathrm{L}_{\mathrm{s}}$ can also be uniquely determined by the stripped Zparameter using the fitting method [1]. However, due to the existence of intrinsic 


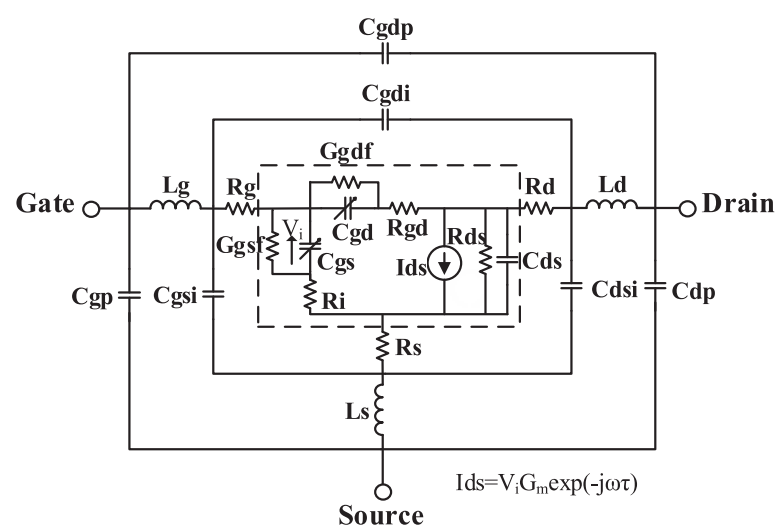

Fig. 1. Typical small-signal equivalent circuit model for deep-submicron GaN HEMTs.

drain-to-source $\left(\mathrm{C}_{\mathrm{dsi}}\right)$ inter-electrode coupling capacitances (IECCs), are not easy to extract.

The use of full-wave electromagnetic simulations is an alternative method to extract the IECCs [8]. But it requires engineers to know all the structural and semiconductor parameters of the device. For most devices, this is obviously not feasible, because the manufacturers generally do not provide detailed information. Moreover, high-precision three-dimensional electromagnetic modeling and simulation are very time-consuming, especially when the capacitors to be extracted are in the $\mathrm{fF}$ level, a small variation in simulation settings will result in erroneous result.

Another commonly used method for extracting the IECCs in GaN HEMTs is proposed by Jarndal et al. [1], which is based on the scanning of the parasitic capacitance value to find the optimal model extrinsic parameters. At low frequencies $(<3 \mathrm{GHz})$, and pinch off conditions, the GaN HEMT can be described by a $\pi$-type network consisting only of the capacitances from Fig. 1 [1]. This $\pi$-type network has three branch capacitors [1]:

$$
\begin{aligned}
& C_{g d o}=C_{g d p}+C_{g d i}+C_{g d} \\
& C_{g s o}=C_{g p}+C_{g s i}+C_{g s} \\
& C_{d s o}=C_{d p}+C_{d s i}+C_{d s}
\end{aligned}
$$

and they can be easily obtained from the measured Y-parameters:

$$
\begin{aligned}
& C_{g d o}=-\operatorname{Im}\left\{\mathrm{Y}_{12}\right\} \\
& C_{g s o}=\operatorname{Im}\left\{\mathrm{Y}_{11}\right\}+\operatorname{Im}\left\{\mathrm{Y}_{12}\right\} \\
& C_{d s o}=\operatorname{Im}\left\{\mathrm{Y}_{22}\right\}+\operatorname{Im}\left\{\mathrm{Y}_{12}\right\}
\end{aligned}
$$

After determining the branch capacitances, the values of $\mathrm{C}_{\mathrm{gp}}, \mathrm{C}_{\mathrm{dp}}$ and $\mathrm{C}_{\mathrm{gdp}}$ are scanned, and each set of scan values corresponds to a set of model parameters (i.e., model parameter vector $\mathbf{P}$ ) and simulation errors $\varepsilon$ with respect to the pinch-off S-parameters. The model parameters with the smallest simulation error are selected as the starting values, and then the final extrinsic parameters are determined using a bidirectional optimization technique [1]. Since there are infinite combinations of capacitances that can satisfy Eq. (1), the proportional relationship between the intrinsic capacitances, the pad capacitances, and the coupling capacitances must be 
pre-defined; and in order to perform two-dimensional capacitance scan, rather than a three-dimensional scan, [1] assumes $\mathrm{C}_{\mathrm{gd}}=\mathrm{C}_{\mathrm{gs}}$ to reduce the number of unknowns. The problem with this method is that the IECCs are only related to the "internal parameters" (e.g., distance between the electrodes, the height of the electrodes, dielectric constant of the active area, etc.), but has nothing to do with the pad capacitors. $\mathrm{C}_{\mathrm{gs}}$ and $\mathrm{C}_{\mathrm{gd}}$ may not be equal for asymmetrical GaN HEMTs even under pinch-off conditions. Incorrect capacitance ratio assumptions and incorrect capacitance scanning range may result in non-physical parameter extraction results.

To solve these problems, a new method is proposed to extract the IECCs, and then the remaining extrinsic parameters of deep-submicron AlGaN/GaN HEMTs. The pinch-off S-parameters under large drain voltage bias are employed to minimize the influence of the intrinsic capacitance on the IECCs extraction. The starting value of $\mathrm{C}_{\text {gdi }}$ is obtained from the extrapolated value of the pinch-off gateto-drain branch capacitor $\left(\mathrm{C}_{\mathrm{gdo}}\right)$ at infinite drain voltage where the $\mathrm{C}_{\mathrm{gd}}$ has its minimum value. $\mathrm{C}_{\mathrm{gsi}}$ is estimated by $\mathrm{C}_{\mathrm{gdi}}$ using the plate capacitance relationship [according to the gate-to-source $\left(\mathrm{L}_{\mathrm{GS}}\right)$ and gate-to-drain spacing $\left(\mathrm{L}_{\mathrm{GD}}\right)$ ]. After the starting values of $\mathrm{C}_{\mathrm{gdi}}$ and $\mathrm{C}_{\mathrm{gsi}}$ are extracted, one-dimensional capacitance scan is performed to determine $\mathrm{C}_{\mathrm{dsi}}$. The optimization method presented in [1] is used to determine the final value of all parasitic parameters. Because of the correct extraction of the $\mathrm{C}_{\text {gdi }}$, non-physical values are avoided in the extraction results across the entire multi-bias domain. Compare with conventional method, this new extraction method is simple and efficient. Small-signal verifications show that this method has very high precision.

\section{Coupling capacitance extraction method}

As a standard procedure for device modeling, the pad capacitances can be deembedded by the test structures, thus, the essence of the difficulty in extraction of the coupling capacitances between the electrodes is that the influence of the intrinsic capacitances during the extraction process.

The new IECCs extraction method described here has been applied to an inhouse AlGaN/GaN HEMT for ka-band power amplifier applications, which is grown on a $\mathrm{SiC}$ substrate with $0.15 \mu \mathrm{m}$ gate-length and $200 \mu \mathrm{m}$ gate-width (4 fingers $\times 50 \mu \mathrm{m}$ finger width). Fig. 2 is the cross-section of the $0.15 \mu \mathrm{m}$ $\mathrm{AlGaN} / \mathrm{GaN}$ HEMT under pinch off condition. The coupling capacitance $\mathrm{C}_{\mathrm{gsi}}, \mathrm{C}_{\text {gdi }}$, and $\mathrm{C}_{\mathrm{dsi}}$ represent the electromagnetic coupling between the metallic electrodes. The area encircles by dashed line represent the depletion region, growing deeper and wider at higher drain-source voltage $\left(\mathrm{V}_{\mathrm{ds}}\right)$ values. The depletion extension toward the drain is denoted by $\mathrm{X}$. The intrinsic capacitance $\mathrm{C}_{\mathrm{gs}}$ and $\mathrm{C}_{\mathrm{gd}}$ represent the charge storage effect in the depletion region. $\mathrm{R}_{\mathrm{i}}$ and $\mathrm{R}_{\mathrm{gd}}$ are the resistances representing the none-zero charging/discharging time in gate-source and gate-drain depletion region, respectively. $C_{d s}$ is the channel capacitance. The geometry, the substrate material as well as the depletion width of the device will affect the value of $C_{d s}[9] . R_{g}, R_{d}$, and $\mathrm{R}_{\mathrm{s}}$ are access resistances. The remaining parasitic parameters, i.e., $\mathrm{C}_{\mathrm{gp}}, \mathrm{C}_{\mathrm{dp}}, \mathrm{C}_{\mathrm{gdp}}, \mathrm{L}_{\mathrm{g}}$, $\mathrm{L}_{\mathrm{d}}, \mathrm{L}_{\mathrm{s}}, \mathrm{R}_{\mathrm{ds}}, \mathrm{G}_{\mathrm{gdf}}, \mathrm{G}_{\mathrm{gsf}}$, and $\mathrm{I}_{\mathrm{ds}}$ are not shown in Fig. 2. 


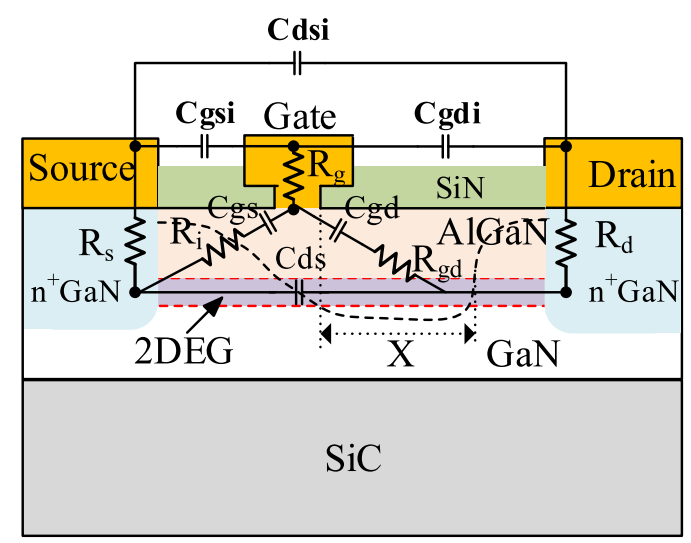

Fig. 2. Schematic diagram of the cross-section of the $0.15 \mu \mathrm{m} \mathrm{AlGaN/}$ GaN HEMT at pinch-off state.

On-wafer static bias S-parameter measurements were performed on the Summit 1200 Cascade-Microtech wafer-probe station, the device was placed on the thermal chuck to stabilize the ambient temperature at 25 degrees Celsius. Agilent N5245A network analyzer was used to measure the S-parameter of the device from $0.4 \mathrm{GHz}$ to $50 \mathrm{GHz}$. The S-parameters were directly de-embedded in Agilent ICCAP software using the measured data of the dummy test structures.
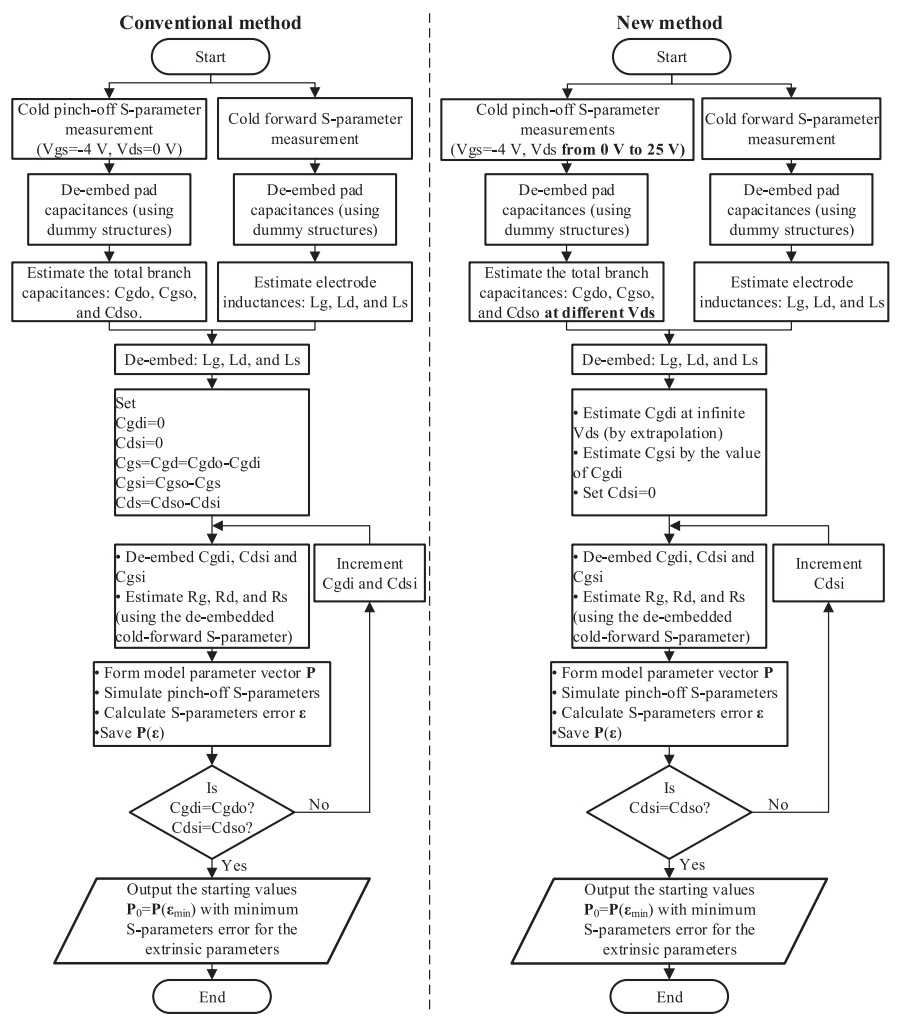

Fig. 3. Measurement-correlated extrinsic parameter starting value generation algorithm, conventional method (left side) and new method (right side). 
S-parameters are the de-embedded data, the pad capacitances $\mathrm{C}_{\mathrm{dp}}, \mathrm{C}_{\mathrm{gp}}$, and $\mathrm{C}_{\mathrm{gdp}}$ disappear from the branch capacitors [see Eq. (1)], and the scanning of the pad capacitances in the conventional method [1] (i.e., $\mathrm{C}_{\mathrm{gdp}}$ from 0 to $0.5 \mathrm{C}_{\mathrm{gdo}}$ with $\mathrm{C}_{\mathrm{gdi}}=2 \mathrm{C}_{\mathrm{gdp}}$, and $\mathrm{C}_{\mathrm{dsp}}$ from 0 to $0.5 \mathrm{C}_{\mathrm{dso}}$ with $\mathrm{C}_{\mathrm{dsi}}=3 \mathrm{C}_{\mathrm{dsp}}$, ) is equivalent to the scanning of the coupling capacitance (i.e., $\mathrm{C}_{\mathrm{gdi}}$ from 0 to $\mathrm{C}_{\mathrm{gdo}}$ and $\mathrm{C}_{\mathrm{dsi}}$ from 0 to $\mathrm{C}_{\mathrm{dso}}$, our results show that scanning to $\mathrm{C}_{\mathrm{dso}}$ is sufficient to determine the optimal value.). Both methods use the pinch-off (For our $0.15 \mu \mathrm{m}$ device, the pinch off voltage is about $-2.2 \mathrm{~V}$.) and cold forward S-parameters to extract the initial value of equivalent circuit element. However, the two methods have three essential differences:

1. For the new method, the coupling capacitance $C_{g d i}$ and $C_{g s i}$ are directly determined from the measured S-parameters without using a capacitance scan.

2. The new method does not need to set the ratio between $C_{g d}$ and $C_{g s}$ in advance.

3. Unlike conventional method [1], which relies solely on pinch-off S-parameter at $\mathrm{V}_{\mathrm{ds}}=0 \mathrm{~V}$, our method utilizes the pinch-off S-parameters with different drain voltage bias to determine the correct value range for $\mathrm{C}_{\mathrm{gdi}}$.

At lower frequencies, the parasitic inductances and resistances were proven to have little effect on the extraction of the branch capacitances $[1,10]$, thus the branch capacitances can be extracted before de-embedding the electrode inductances. Using the measured low frequencies $(<3 \mathrm{GHz})$ pinch-off $\left(\mathrm{V}_{\mathrm{gs}}=-4 \mathrm{~V}, \mathrm{~V}_{\mathrm{ds}}=\right.$ $0 \mathrm{~V})$ S-parameters, $\mathrm{C}_{\mathrm{gdo}}, \mathrm{C}_{\mathrm{gso}}$ and $\mathrm{C}_{\mathrm{dso}}$ are extracted to be $62.82 \mathrm{fF}, 70.24 \mathrm{fF}$, and $46.75 \mathrm{fF}$, respectively. Furthermore, we extracted the pinch-off $\left(\mathrm{V}_{\mathrm{gs}}=-4 \mathrm{~V}\right)$ values of $\mathrm{C}_{\mathrm{gdo}}$ at different drain voltages. As can be seen in Fig. 4 , as $\mathrm{V}_{\mathrm{ds}}$ increases, $\mathrm{C}_{\mathrm{gdo}}$ gets smaller. This is because, as the drain voltage increases, the depletion region grows toward the drain, resulting in less charge storage in the gate-drain region, which makes the $C_{g d}$ smaller. Since $C_{g d i}$ is independent of the bias voltage, the total capacitance $\mathrm{C}_{\mathrm{gdo}}$ becomes smaller. Ideally, when $\mathrm{V}_{\mathrm{ds}}$ becomes infinite, the entire gate-drain region is completely depleted and the influence of $\mathrm{C}_{\mathrm{gd}}$ on $\mathrm{C}_{\mathrm{gdi}}$ extraction becomes minimal. Thus, we can plot the $C_{g d o}$ as a function of $1 / V_{d s}$, the $C_{g d o}$ value at $1 / \mathrm{V}_{\mathrm{ds}}=0$ (i.e., where $\mathrm{V}_{\mathrm{ds}}$ is infinite) can be used as the starting value of $\mathrm{C}_{\text {gdi }}$. A higher drain voltage may better describe the variation of $\mathrm{C}_{\text {gdo }}$ with drain voltage,

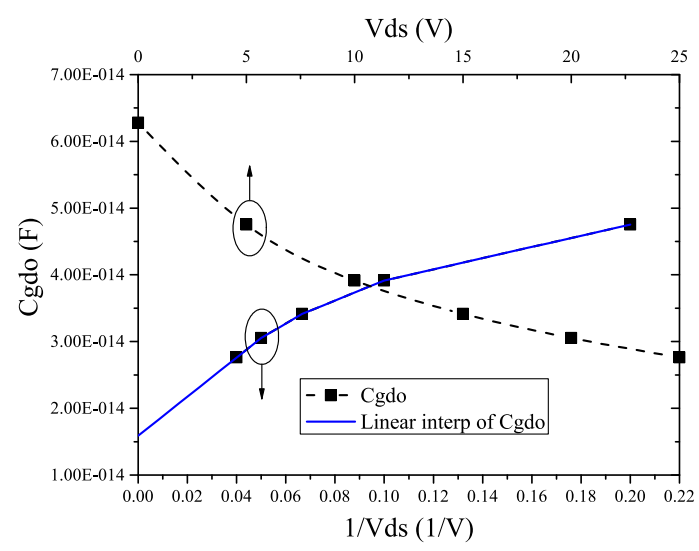


but in order to protect the device, our maximum drain voltage is measured to $25 \mathrm{~V}$. The extrapolated value of $\mathrm{C}_{\mathrm{gdo}}$ is $15.89 \mathrm{fF}$, which is only $25 \%$ of the value (i.e., $62.82 \mathrm{fF}$ ) at $\mathrm{V}_{\mathrm{ds}}=0 \mathrm{~V}$.

The pinch-off value of $\mathrm{C}_{\mathrm{gso}}$ showed little variation with $\mathrm{V}_{\mathrm{ds}}$. Since $\mathrm{C}_{\mathrm{gdi}}$ has been known and the coupling capacitances between the electrodes are similar to the plate capacitors, we can estimate the $\mathrm{C}_{\mathrm{gsi}}$ by the ratio between $\mathrm{L}_{\mathrm{GS}}$ and $\mathrm{L}_{\mathrm{GD}}$. For our $0.15 \mu \mathrm{m}$ device, $\mathrm{L}_{\mathrm{GS}}=0.85 \mu \mathrm{m}$ and $\mathrm{L}_{\mathrm{GD}}=1.7 \mu \mathrm{m}$, hence $\mathrm{C}_{\mathrm{gsi}}$ is at least twice that of $\mathrm{C}_{\mathrm{gdi}}\left(\mathrm{C}_{\mathrm{gsi}}\right.$ also contains the crossover capacitances due to air-bridge source connections). Thus, $31.78 \mathrm{fF}$ is a conservative estimate for $\mathrm{C}_{\mathrm{gsi}}$.

The pinch-off value of $\mathrm{C}_{\mathrm{dso}}$ also showed little variation with $\mathrm{V}_{\mathrm{ds}}$. After the $\mathrm{C}_{\mathrm{gdi}}$ and $\mathrm{C}_{\mathrm{gsi}}$ are determined, the starting value of $\mathrm{C}_{\mathrm{dsi}}$ is determined using the capacitance scanning method presented in [1]. The $C_{\mathrm{dsi}}$ value is scanned from 0 to $50 \mathrm{fF}$ (slightly larger than the pinch-off value of $\mathrm{C}_{\mathrm{dso}}$ ), each $\mathrm{C}_{\mathrm{dsi}}$ scan value corresponds to a set of access resistances and intrinsic parameter values (extracted using the method described in [1]). The error between simulated and measured pinch-off S-parameter can be calculated according to the following expressions:

$$
\text { Error }=\sum_{i, j=1}^{2} \sqrt{\frac{\sum_{n=1}^{N}\left|S_{i j, n}^{\text {meas }}-S_{i j, n}^{\text {calc }}\right|^{2}}{\sum_{n=1}^{N}\left|S_{i j, n}^{\text {meas }}\right|^{2}}} \quad i, j=1,2 \quad n=1,2, \ldots, N,
$$

where $S_{i j, n}^{\text {meas }}$ and $S_{i j, n}^{c a l c}$ are the measured and calculated S-parameter at specific frequency, respectively. $\mathrm{N}$ is the total number of frequency data points. When $\mathrm{C}_{\mathrm{dsi}}$ is equal to $30 \mathrm{fF}$, the corresponding pinch-off S-parameter error is minimum, which is 0.1049 . Thus $30 \mathrm{fF}$ can be used as the starting value for $\mathrm{C}_{\mathrm{dsi}}$. The model errors corresponding to the scan values are shown in Fig. 5a.

We also extracted the starting value of the device extrinsic parameters according to the method presented in [1], as shown in Fig. 5b, a two-dimensional capacitance scanning was performed to find out the optimal value for $\mathrm{C}_{\mathrm{gdi}}$ and $\mathrm{C}_{\mathrm{dsi}}$. The minimum calculation error is 0.0815 when $\mathrm{C}_{\mathrm{gdi}}$ and $\mathrm{C}_{\mathrm{dsi}}$ are equal to $55 \mathrm{fF}$ and $35 \mathrm{fF}$, respectively. Obviously, $55 \mathrm{fF}$ is much larger than the value of $\mathrm{C}_{\mathrm{gdo}}$ (i.e., $27.60 \mathrm{fF}$ when $\mathrm{V}_{\mathrm{ds}}=25 \mathrm{~V}$ ). Therefore, the use of conventional method may overestimate the value of $\mathrm{C}_{\mathrm{gdi}}$, and underestimate the value of $\mathrm{C}_{\mathrm{gd}}$ for the sum of the two is certain.

After the starting value of all extrinsic parameters are determined, a MATLAB program [11] based on the optimization method described in [1] was used to obtain the final value of these parameters. The results are shown in Table I.

It can be observed that the optimized values are close to the starting values; this confirms the reliability of the new starting value extraction method. However, for the conventional method, the larger $C_{\text {gdi }}$ leads to a large difference between the initial and final values of the gate and drain resistances. The final values of the two methods derived from the same optimization algorithm are very close, except for $\mathrm{C}_{\text {gdi }}$. We find that the $\mathrm{C}_{\mathrm{gdi}}$ obtained by the conventional method (i.e., $44.00 \mathrm{fF}$ ) is close to the $\mathrm{C}_{\mathrm{gd}}$ value (i.e., $62.82-16.27=46.55 \mathrm{fF}$ ) extracted by the new method and vice versa for $C_{g d}$. Due to the compensation of intrinsic capacitance [12], 


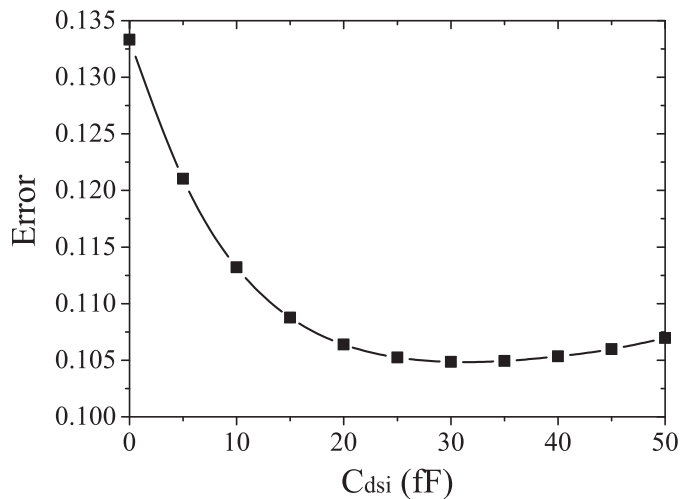

(a)

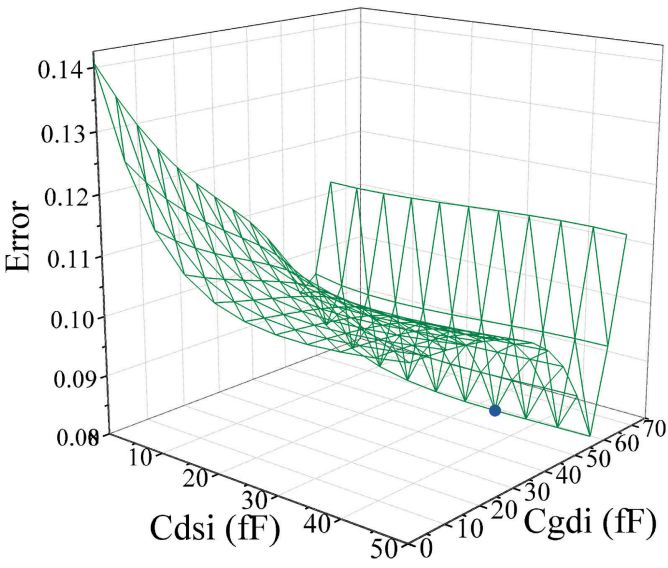

(b)

Fig. 5. Capacitance value scanning to determine the starting value of extrinsic parameters: (a) new method, one-dimensional capacitance scan, (b) conventional method, two-dimensional capacitance scan.

Table I. The starting values and final values for the extrinsic parameters of the $0.15 \mu \mathrm{m}$ GaN HEMT.

\begin{tabular}{|c|c|c|c|c|}
\hline & \multicolumn{2}{|c|}{ starting values } & \multicolumn{2}{c|}{ final values } \\
\hline Parameters & $\begin{array}{c}\text { Conventional } \\
\text { method }\end{array}$ & New method & $\begin{array}{c}\text { Conventional } \\
\text { method }\end{array}$ & New method \\
\hline $\mathrm{C}_{\mathrm{gdi}}$ & $55 \mathrm{fF}$ & $15.89 \mathrm{fF}$ & $44.00 \mathrm{fF}$ & $16.27 \mathrm{fF}$ \\
\hline $\mathrm{C}_{\mathrm{gsi}}$ & $62.43 \mathrm{fF}$ & $31.78 \mathrm{fF}$ & $51.17 \mathrm{fF}$ & $48.50 \mathrm{fF}$ \\
\hline $\mathrm{C}_{\mathrm{dsi}}$ & $35 \mathrm{fF}$ & $30 \mathrm{fF}$ & $37.74 \mathrm{fF}$ & $35.85 \mathrm{fF}$ \\
\hline $\mathrm{L}_{\mathrm{g}}$ & $30.05 \mathrm{pH}$ & $30.05 \mathrm{pH}$ & $24.20 \mathrm{pH}$ & $25.98 \mathrm{pH}$ \\
\hline $\mathrm{L}_{\mathrm{d}}$ & $20.07 \mathrm{pH}$ & $20.07 \mathrm{pH}$ & $21.66 \mathrm{pH}$ & $24.13 \mathrm{pH}$ \\
\hline $\mathrm{L}_{\mathrm{s}}$ & $2.47 \mathrm{pH}$ & $2.47 \mathrm{pH}$ & $9.70 \mathrm{pH}$ & $7.65 \mathrm{pH}$ \\
\hline $\mathrm{R}_{\mathrm{g}}$ & $1.95 \mathrm{Ohm}$ & $0.61 \mathrm{Ohm}$ & $0.52 \mathrm{Ohm}$ & $0.65 \mathrm{Ohm}$ \\
\hline $\mathrm{R}_{\mathrm{d}}$ & $4.70 \mathrm{Ohm}$ & $4.20 \mathrm{Ohm}$ & $3.73 \mathrm{Ohm}$ & $4.14 \mathrm{Ohm}$ \\
\hline $\mathrm{R}_{\mathrm{s}}$ & $2.75 \mathrm{Ohm}$ & $3.28 \mathrm{Ohm}$ & $2.80 \mathrm{Ohm}$ & $3.05 \mathrm{Ohm}$ \\
\hline $\begin{array}{c}\mathrm{S}-\text { parameter } \\
\text { Error }\end{array}$ & 0.0815 & 0.1049 & 0.0420 & 0.0414 \\
\hline
\end{tabular}




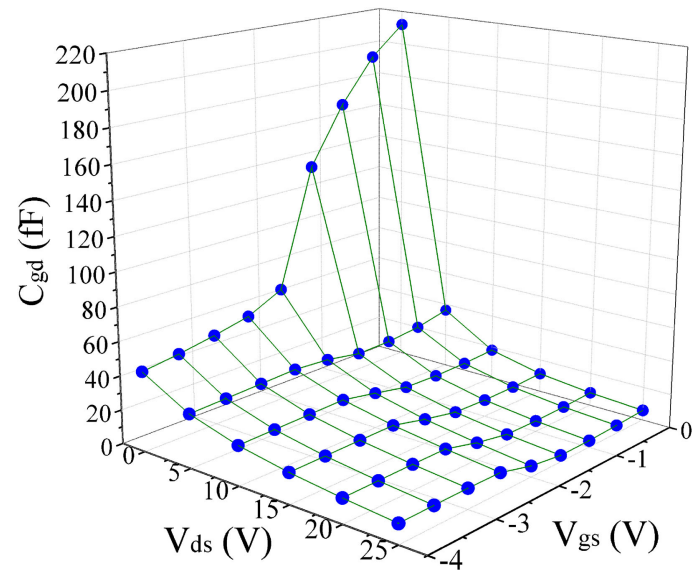

(a)

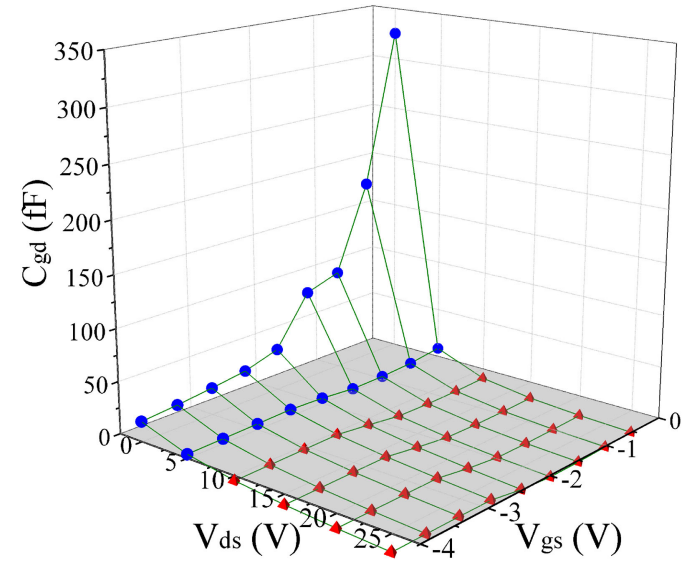

(b)

Fig. 6. Multi-bias Cgd values extracted from the (a) new method, and (b) conventional method, dots: extraction value larger than zero, tetrahedrons: extraction value less than zero.

incorrect $\mathrm{C}_{\mathrm{gdi}}$ value can also obtain good fitting for pinch-off S-parameter. However, if the incorrect extrinsic parameters are used to extract the intrinsic parameters of the device, non-physical values will be produced. Fig. 6 shows the $C_{g d}$ extracted from these two sets of extrinsic parameters. When $\mathrm{V}_{\mathrm{ds}}$ is larger than $5 \mathrm{~V}$, the $\mathrm{C}_{\mathrm{gd}}$ extracted by the conventional method is less than zero.

S-parameter simulation error obtained by the new method for the entire multibias domain are shown in Fig. 7. The average error in the entire domain is about $5.36 \%$, showing a very high extraction accuracy of the new extraction method.

According to the scaling rule introduced in [10], and based on the small-signal model of the $4 \times 50 \mu \mathrm{m}$ device, a scalable small-signal model has been established, and the S-parameter simulation of a $4 \times 60 \mu \mathrm{m}$ GaN HEMT on the same wafer was carried out. The simulation accuracy of the two methods should be compared at the operating point of the device (i.e., $\mathrm{V}_{\mathrm{ds}}=20 \mathrm{~V}, \mathrm{~V}_{\mathrm{gs}}=-1.5 \mathrm{~V}$ ), but since the $\mathrm{C}_{\mathrm{gd}}$ of the conventional method at this bias point is less than 0 , we compare the accuracy of these two models at $\mathrm{V}_{\mathrm{ds}}=5 \mathrm{~V}$ and $\mathrm{V}_{\mathrm{gs}}=-1 \mathrm{~V}$. As can be seen from Fig. 8, both magnitude and phase of the S-parameter show that the new method has higher accuracy. 


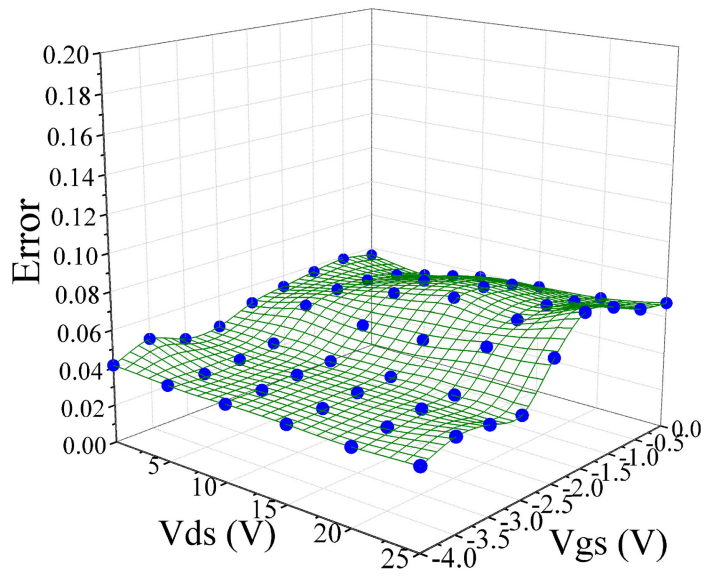

Fig. 7. Multi-bias S-parameter simulation error of the new method.

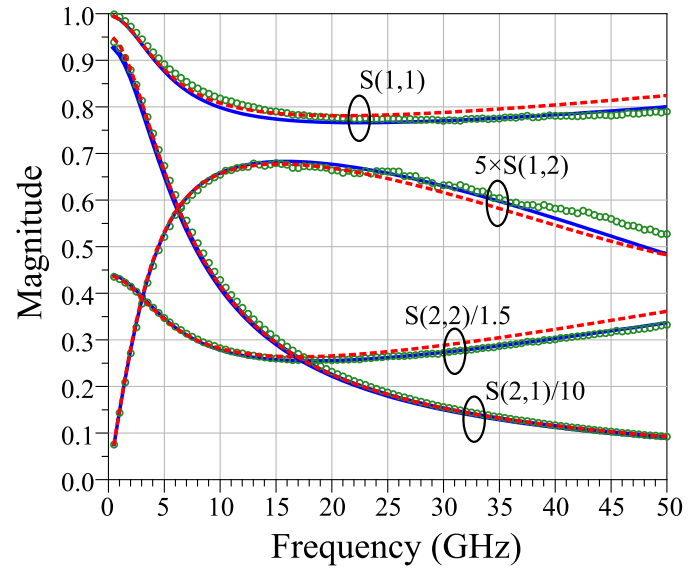

(a)

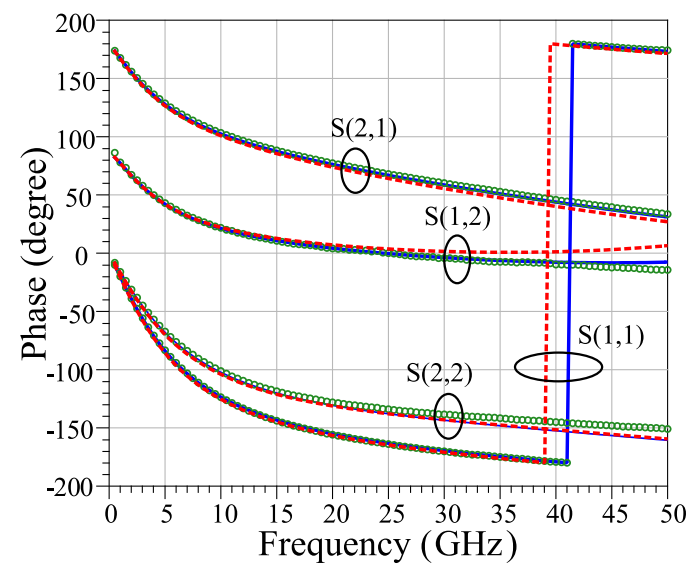

(b)

Fig. 8. Comparison of the measured data (circles) of a $0.15 \mu \mathrm{m} \mathrm{GaN}$ HEMT with a $4 \times 60 \mu \mathrm{m}$ gate width with simulation results (new method: solid lines, conventional method: dashed lines): (a) magnitude and (b) phase of the $\mathrm{S}$-parameter at $\mathrm{V}_{\mathrm{ds}}=5 \mathrm{~V}$, $\mathrm{V}_{\mathrm{gs}}=-1 \mathrm{~V}$.

\section{Conclusion}

In this paper, we proposed a new method to extract the inter-electrode coupling capacitance of deep-submicron GaN HEMTs. The method utilizes the pinch-off 
S-parameters with different drain voltage bias to determine the correct value for $\mathrm{C}_{\mathrm{gdi}}$. $\mathrm{C}_{\mathrm{gsi}}$ can be estimate by $\mathrm{C}_{\mathrm{gdi}}$ using the ratio between $\mathrm{L}_{\mathrm{GD}}$ and $\mathrm{L}_{\mathrm{GS}}$. This not only avoids over-estimation of $\mathrm{C}_{\mathrm{gdi}}$ (which may cause non-physical values in the intrinsic parameter extractions), but also reduces the capacitance scan dimensions required by conventional methods. The optimization results show that the final values are close to the starting values, the validity of the new starting value extraction method is verified. Multi-bias S-parameter simulation results show that this new method has high accuracy. The extraction process is simple and efficient, and can be used for rapid extraction of parasitic parameters for deep-submicron GaN HEMTs. 